\title{
Correspondence between neurological symptoms and outcome of quantitative sensory testing in the hand-arm vibration syndrome
}

\author{
LENA EKENVALL, ' GÖSTA GEMNE, ${ }^{2}$ R TEGNER ${ }^{3}$ \\ From the Department of Occupational Medicine, ${ }^{1}$ Karolinska Sjukhuset, Stockholm, Unit of Occupational \\ Medicine, ${ }^{2}$ National Institute of Occupational Health, Solna, and Department of Neurology, ${ }^{3}$ Karolinska \\ Sjukhuset, Stockholm, Sweden
}

\begin{abstract}
To evaluate neurological symptoms in the vibration syndrome, 55 patients with vascular and neurological symptoms in the hands who had been exposed to vibration were examined. Theip exposure to vibration was estimated and neurological and vascular symptoms were evaluated according to symptom scales. Temperature thresholds were measured on the right thenar eminences and on the distal volar aspect of the second and third fingers held together on both sides. Vibrations thresholds were measured dorsally on the second and fifth metacarpal bones and on the second andfifth fingers proximal to the nail roots. Subjects with advanced neurological symptoms had higher temperature and vibration thresholds than subjects with less advanced symptoms. No such relation was found between vascular symptoms and the outcome of sensory testing. Thus neurological but not ${ }^{n}$ vascular symptoms are reflected by the outcome of quantitative sensory testing. In subjects witho advanced neurological symptoms the tests gave a high proportion of abnormal results, indicating the these tests may be used for the diagnosis of vibration syndrome on an individual basis. Patients with advanced vascular and neurological symptoms had higher exposure dose scores than patients wh less advanced symptoms, indicating a dose response relation between vibration "dose" añd" neurological and vascular symptoms.
\end{abstract}

Episodic numbness of fingers and paraesthesias in the hands and arms are frequently reported by operators of hand held vibrating tools. ${ }^{1}$ In advanced cases loss of sensory perception ${ }^{2}$ and reduced manipulative dexterity occur. ${ }^{3}$ These symptoms may cause more disability than vibration white finger. The latter disorder has been extensively studied with respect to dose response relations and to achieve objective verification of the disease. Neurological symptoms included in the hand-arm vibration syndrome have not been as extensively studied, perhaps because they have not always been separated from Raynaud's phenomenon. There is now evidence that the different components of vibration syndrome may develop independently. ${ }^{4}$

This study was designed to evaluate results of quantitative sensory threshold measurements in relation to neurological and vascular symptoms and to vibration exposure in patients with suspected vibration syndrome.
Subjects and methods

\section{SUBJECTS}

Seventy six consecutive patients who had beem exposed to vibration examined at the department of occupational medicine, Karolinska Hospital, and referred to the department of neurology for determis nation of sensory thresholds in the hands, were evaluated. The following criteria were used to include patients in the final study group.

(1) Exposure to hand-arm vibration possible to evaluate according to the method described belows Two patients were excluded; both were dentists whos had been working with high speed drills. The remaining patients had been working in many differen occupations, including grinders, construction work $\omega_{0}$ ers, electricians, car mechanics and repair shop work ers, and agricultural and road machine operators.

(2) No other disease possibly interfering with the results of sensory testing or giving neurological of vascular symptoms. Sixteen patients were excluded for 
the following reasons: Raynaud's disease 3, polyneuropathies 5, carpal tunnel syndrome 1, entrapment of the ulnar nerve at the elbow 2, plexus damage 1 , thrombosis of the ulnar artery 1 , diabetes 1 , suspected malingering 2 .

(3) Vascular and neurological symptoms possible to evaluate according to symptom scales. Three patients with atypical symptoms were excluded.

The final study group consisted of 55 patients who had been exposed to vibration with neurological or vascular symptoms, or both, in their hands. Electroneurophysiological examination was performed in 44 of these patients. The remaining 11 patients had no or slight neurological symptoms in the hands.

\section{SYMPTOM SCALING}

The vascular symptoms of the patients were evaluated from the case histories. The grading was made separately for each hand according to the revised Taylor-Pelmear symptom scale ${ }^{5}$ with the modification that the number of fingers included in the disease process were not considered. The neurological symptoms, separately for each hand, were similarly evaluated according to the following symptom scale, adopted from Brammer et al. ${ }^{6}$

0 No neurological symptoms from the hands.

1 Intermittent numbness with or without tingling.

2 Persistent numbness or tingling.

3 Intermittent or persistent numbess or tingling and reduced sensory perception or manipulative dexterity.

All symptoms must be present in the warm hand. Cases with neurological symptoms appearing only in close temporal relation to work with hand held vibrating tools were categorised as stage 0 .

\section{ESTIMATION OF VIBRATION EXPOSURE}

For each subject, an exposure score was estimated using the following method. The degree of exposure was characterised with the help of an index, denoting the typical average vibration acceleration of the tools. This was done on the basis of experience obtained in measurements over the past 15 years in Scandinavia and the United Kingdom. 'The degree of exposure was categorised into three groups: index 1 , for tools with acceleration $<3 \mathrm{~m} / \mathrm{s}^{2}$; index $2,3-10 \mathrm{~m} / \mathrm{s}^{2}$; and index 3 , $>10 \mathrm{~m} / \mathrm{s}^{2}$. For subjects with mixed exposure from different tool sets, half unit steps between these indexes were also used. The number of years during which he had been working with a specific set of tools (such as chisel hammers or rock drills) was noted and the vibration exposure time was estimated by weighting with factors ranging from 0.25 to 1.0 . This weighted exposure time index was then multiplied with the degree of exposure to obtain a score estimating the exposure dose.

\section{DETERMINATION OF SENSORY THRESHOLDS}

Quantitative assessments of thermal sensation were obtained by the Marstock method as described by Fruhstorfer et al. ${ }^{8}$ The thermostimulator, operating on the Peltier principle, had a rectangular surface of $25 \times 50 \mathrm{~mm}$. Measurements were made on the thenar eminence of the right hand and on the distal volar aspect of the second and third fingers held together on both hands. Warm/cold threshold difference (neutral zone) was determined.

Vibration perception thresholds were measured according to Goldberg and Lindblom ${ }^{9}$ with a hand held vibrameter (Somedic AB, Stockholm, Sweden) producing a $100 \mathrm{~Hz}$ sine wave at an application pressure of $40 \mathrm{kPa}$. An accelerometer continuously recorded the movement of the stimulating probe $\left(1.3 \mathrm{~cm}^{2}\right)$ and the displacement amplitude (peak to peak, micrometer) was displayed digitally. Measurements were made on both hands on the dorsal aspect of the second and fifth metacarpal bones and dorsally on the second and fifth digits just proximal to the nail roots.

Motor and sensory conduction velocities and amplitudes of action potentials were determined in the median and ulnar nerves of both sides. Electromyographic recordings were made from intrinsic hand muscles. All the measurements were performed at the department of clinical neurophysiology. Karolinska Hospital, according to standard techniques. Conduction velocities were corrected for age and temperature according to Ludin. ${ }^{10}$ When signs of polyneuropathy were present, conduction velocities were also determined in the sural and peroneal nerves on one side.

\section{STATISTICAL METHODS}

A $t$ test (two sided) with a level of significance of p $<0.05$ was used. The chi-squared test was used to analyse relations between sensory and vascular symptoms.

\section{Results}

\section{AGE AND EXPOSURE}

The mean and median age of the patients were 48 (standard deviation, 9.5; range, 22-65 years). The mean exposure dose score was 45.6 (SD 23.6; range, 10.6-129.0).

\section{NEUROLOGICAL SYMPTOMS}

Thirteen patients had no neurological symptoms from the right hand. Eleven had symptoms corresponding to stage 1,16 to stage 2 , and 15 to stage 3 . The corresponding numbers for the left hand were 19, 12, 13 , and 11. 
Table 1 Mean perception thresholds for temperature and vibration on the right hand in the different sensory stages. The normative data in unexposed healthy men are from Ekenvall et al. ${ }^{11}$ (SD in parentheses)

\begin{tabular}{|c|c|c|c|c|c|}
\hline & \multirow[b]{2}{*}{$\begin{array}{l}\text { Normative data } \\
(n=46)\end{array}$} & \multicolumn{4}{|l|}{ Sensory stage } \\
\hline & & $\begin{array}{l}0 \\
(n=13)\end{array}$ & $l n=11)$ & $\frac{2}{(n=16)}$ & 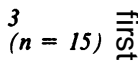 \\
\hline $\begin{array}{l}\text { Age }(y) \\
\text { Neutral zone, }{ }^{\circ} \mathrm{C}:\end{array}$ & $43(10)$ & $46(8)$ & $41(11)$ & $50(9)$ & $53(7)$ \\
\hline $\begin{array}{l}\text { Thenar } \\
\text { Digits } 2+3 \\
\text { Vibration threshold (um). }\end{array}$ & $\begin{array}{l}2 \cdot 7(0 \cdot 9) \\
5 \cdot 2(2 \cdot 5)\end{array}$ & $\begin{array}{l}2.9(0.7) \\
6.5(3.6)\end{array}$ & $\begin{array}{r}3.0(1.0) \\
11.6(5 \cdot 8)\end{array}$ & $\begin{array}{r}4 \cdot 3(2 \cdot 0) \\
10 \cdot 4(4 \cdot 4)\end{array}$ & $\begin{aligned} & 5.5(3.1) \frac{\overline{\bar{~}}}{17 \cdot 1(8.9)} \\
& \bar{D}\end{aligned}$ \\
\hline $\begin{array}{l}\text { Vibration threshold }(\mu \mathrm{m}) \text { : } \\
\text { 2nd Metacarpal } \\
\text { 5th Metacarpal } \\
\text { Digit } 2 \\
\text { Digit } 5\end{array}$ & $\begin{array}{l}0.28(0.15) \\
0.54(0.26) \\
0.30(0.15)\end{array}$ & $\begin{array}{l}0.33(0.19) \\
0.39(0.25) \\
0.56(0.38) \\
0.74(0.59)\end{array}$ & $\begin{array}{l}0.55(0.47) \\
0.43(0.27) \\
0.72(0.46) \\
0.73(0.41)\end{array}$ & $\begin{array}{l}0.55(0.29) \\
0.67(0.55) \\
1.00(0.76) \\
0.92(0.41)\end{array}$ & $\begin{array}{l}1.03(0.91 d) \\
0.97(0.729) \\
2.07(2.58) \\
1.99(2.209)\end{array}$ \\
\hline
\end{tabular}

\section{VASCULAR SYMPTOMS}

In the right hand nine patients had vascular symptoms corresponding to revised Taylor-Pelmear stage 0, seven to stage 1,19 to stage 2 , and 20 to stage 3 . In the left hand $11,7,18$, and 19 patients were in the respective vascular symptom stages.

Advanced vascular symptoms were equally common in patients with advanced neurological symptoms (stages 2 and 3 ) as in those with less advanced (stages 0 and 1).

\section{SENSORY THRESHOLDS}

Table 1 shows the results of the sensory threshold measurements of the right hand. Subjects with advanced neurological symptoms had more impaired temperature sensitivity $(p<0.01$ on both stimulation areas) and higher vibration thresholds ( $p<0.03$ on all stimulation areas) than subjects with less advanced symptoms.

On the left hand only the vibration threshold on the second metacarpal bone showed a statistically significant difference between subjects with advanced and less advanced neurological symptoms $(p<0.02)$ but the mean values were consistently higher in the group with advanced symptoms (table 2).

When the subjects were divided into two groups according to the severity of their vascular symptoms, no statistically significant group differences in mean sensory thresholds were found on either hand.

The figure shows the outcome of the sensory testing on the right hand on an individual basis (normal or pathological). The normative data are standardised for age. ${ }^{11}$ The vibration threshold on the fifth metacarpal bone was presumed to be identical to that on the second metacarpal, since normative values for this stimulation area do not exist. The number of pathological tests increased with increasing sensory stages; in sensory stage 3 only one person had normal values at all stimulation areas. In sensory stage 1 six of 11 patients had abnormal results in temperature thresholds, whereas three of 11 had abnormal vibration thresholds. In sensory stage 3,11 of 15 patients ha雨 impaired temperature sensitivity, and nine of 1 . patients had abnormal vibration thresholds at one or more stimulation areas on the right hand. On the lefţ hand, five of 19 patients in sensory stage 0 had abnormal perception thresholds at one or two (1 case stimulation areas, whereas in sensory stage 3 of 15 patients, 10 had abnormal results at one ( 2 cases) or more stimulation areas.

Altogether 15 (of 44 ) patients had pathologicas results in the electroneurophysiological examination of the right hand, one in sensory stage 0 , two in stage $1 \stackrel{+}{+}$ five in stage 2 , and seven in stage 3 of the right hand.

\section{EXPOSURE}

Patients with advanced vascular and neurolog symptoms had a higher mean exposure index the those with less advanced symptoms $(p<0.0005)$ whereas patients with mixed advanced and less advaneD ced neurological and vascular symptoms had exposure scores in between (table 3 ). Table 4 shows the exposure dose scores in the different sensory and vascula? stages. Patients with vibration thresholds above the common median for all patients on the right hand had. higher mean exposure dose score than patients with below median vibration thresholds ( $p<0.05$ on $a$ stimulation areas). No such relation was found be? tween temperature thresholds and exposure dose.

Table 2 Perception thresholds on the left hand in sensory stages $0+1$ and $2+3$. Mean and (SD) are shown with $p$ values when comparing the groups

\begin{tabular}{|c|c|c|c|}
\hline & \multicolumn{2}{|c|}{ Sensory stage } & \multirow[b]{2}{*}{ p Value } \\
\hline & $\begin{array}{l}0+1 \\
(n=31)\end{array}$ & $\begin{array}{l}2+3 \\
(n=24)\end{array}$ & \\
\hline $\begin{array}{l}\text { Neutral zone, }{ }^{\circ} \mathrm{C} \text { : } \\
\text { Digits } 2+3 \\
\text { Vibration threshold }(\mu \mathrm{m}) \text { : }\end{array}$ & & $11 \cdot 8 \quad(8 \cdot 6)$ & 0.14 ర్ \\
\hline $\begin{array}{l}\text { 2nd Metacarpal } \\
\text { 5th Metacarpal } \\
\text { Digit } 2 \\
\text { Digit } 5\end{array}$ & $\begin{array}{l}0.37(0.21) \\
0.55(0.38) \\
0.69(0.46) \\
0.74(0.47)\end{array}$ & $\begin{array}{l}0.66(0.52) \\
0.93(1.07) \\
1.36(1.84) \\
1.42(1.86)\end{array}$ & 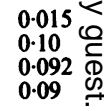 \\
\hline
\end{tabular}




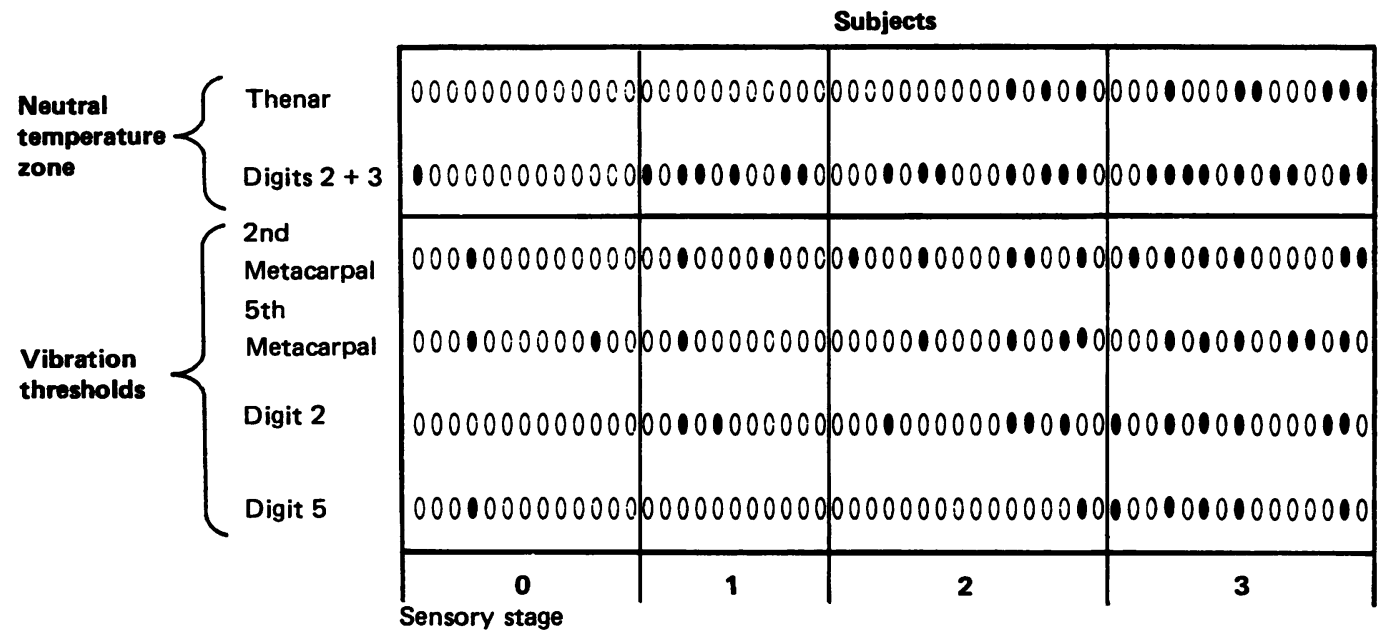

Results of sensory testing $(O=$ normal, $\bigcirc=$ pathological) in relation to sensory symptoms (right hand) in patients.

\section{Discussion}

The present study shows that the neurological, but not vascular, symptoms of men exposed to vibration are reflected by the outcome of quantitative sensory testing. Neurological symptoms may cause a greater disability than vascular and may also remain after exposure has ceased, whereas the vascular symptoms decrease after reduction of exposure ${ }^{12}$ with a reversion to normal circulatory status (G Gemne, I Pyykkö, unpublished data). Therefore, neurological symptoms should be evaluated at an early stage. The techniques used in the present study seem well suited for that purpose.

Temperature and vibration thresholds were abnormal at one or more stimulation areas in 14 of 15 patients with advanced neurological symptoms in the right hand and in 10 of 11 with advanced symptoms in the left. Thus, also on individual basis, these tests may be used to diagnose vibration syndrome, and at least for sensory stage 3 they may be sensitive enough to be used in evaluating insurance cases. Since all the subjects in this study had been exposed to vibration and referred to a clinic of occupational medicine for

Table 3 Exposure scores in relation to severity of sensory and vascular symptoms (right hand). Mean $\pm S D$ are shown. (Number of patients in parentheses)

\begin{tabular}{lll}
\hline & \multicolumn{2}{l}{ Sensory stage } \\
\cline { 2 - 3 } Vascular stage & $0+1$ & $2+3$ \\
\hline $0+1$ & $25 \pm 12(7)$ & $42 \pm 21(9)$ \\
$2+3$ & $45 \pm 25(17)$ & $54 \pm 23(22)$ \\
\hline
\end{tabular}

specialist evaluation, the frequency of false positive tests in subjects exposed to vibration cannot be estimated. Nevertheless, only three of 11 subjects without sensory symptoms had abnormal test results in any of the examined areas of the right hand, and the mean sensory thresholds in this patient group were similar to those obtained in a group of healthy men not exposed to vibrating tools."

In the present subjects sensory thresholds correlated less well with the symptoms in the left hand than in the right. The patients may have been more apt to notice neurological symptoms from the dominant, most often the right, hand. If this is correct it reflects the importance of thorough history taking.

In the present study subjects were examined at different times of the day. A few patients may therefore have worked with vibrating tools on the day of the examination. Thus it cannot be excluded that a temporary decrease in vibration sensibility may have contributed to the abnormal results. ${ }^{13}$ The finding that patients in sensory stage 0 had as low vibration thresholds as unexposed men, however, indicates that the contribution of a temporary threshold change was minor, if present at all.

Table 4 Exposure dose scores in the different sensory and vcascular stages. Mean and (SD) are shown

\begin{tabular}{lllll}
\hline & 0 & $l$ & 2 & 3 \\
\hline \multirow{4}{*}{$\begin{array}{c}\text { Sensory stage } \\
\text { Right hand }\end{array}$} & $37(14)$ & $43(32)$ & $49(22)$ & $52(24)$ \\
Left hand & $38(13)$ & $48(36)$ & $46(20)$ & $56(22)$ \\
& & & \\
Right hand & $36(23)$ & $32(14)$ & $47(25)$ & $53(23)$ \\
Left hand & $35(23)$ & $33(12)$ & $47(26)$ & $55(22)$ \\
\hline
\end{tabular}


Abnormal temperature thresholds were more common and seemed to have developed at an earlier stage than abnormal vibration thresholds. This is in accordance with results obtained in animal experiments, where vibration was shown to damage thin nerve fibres in the exposed extremity first (G Lundborg, personal communication). In an earlier study abnormal neutral zones was the most common finding in patients exposed to vibration with neurological symptoms in their hands."

The low number of abnormal electroneurophysiological examinations does not mean that this examination is unnecessary. Apart from 15 abnormal results obtained in the study group, two cases of entrapment of the ulnar nerve at the elbow, one carpal tunnel syndrome, one root or plexus damage, and five polyneuropathies were found in the initial group of subjects.

The severity of neurological and vascular symptoms increased with the exposure dose scores and above median perception thresholds for vibration were also reflected in high mean exposure dose scores. This suggests a dose response relation between vibration exposure, symptoms, and vibration perception. Temperature thresholds were not related to exposure dose in the same way as vibration thresholds. This may be due to an earlier development of abnormal temperature thresholds, making abnormality relatively common also in patients with "low" exposure dose scores. Since our study subjects always had vascular if they had no neurological symptoms, the influence of dose on neurological symptoms is underestimated.

Separate sensory and vascular stagings of symptoms in the vibration syndrome have been proposed. ${ }^{56}$ The suggested sensory staging includes objective measurement of sensory perception. The sensory staging used in the present study was based exclusively on the patients' description of their symptoms, a method used both in the earlier ${ }^{14}$ and in the revised vascular symptom scales. A symptom scale has the advantage that it does not require devices for sensory testing and it may therefore be used to screen exposed populations. The symptom scale may also be used to evaluate the relevance of new examination techniques of the hands. To our knowledge, these techniques have not yet been used in screening surveys of exposed populations for the early detection of deteriorate sensory function. Individual monitoring of sensor perception thresholds may well detect nerve damage early enough to prevent incapacitating neurologicat symptoms.

\section{References}

1 Pyykkö I. The prevalence and symptoms of traumatic vasospastffe disease among lumberjacks in Finland. A field study. Work anब Environmental Health 1974;11:118-31.

2 Marshall J, Poole EW, Reynard WA. Raynaud's phenomenon dure to vibrating tools. Lancet $1954 ; \mathrm{i}: 1151-6$.

3 Banister PA, Smith FV. Vibration-induced white fingers and manipulative dexterity. Br J Ind Med 1972;29:264-7.

4 Pyykkö I, Korhonen OS, Färkkilä MA, Starck JP, Aatola SA. longitudinal study of the vibration syndrome in Finnish forestro workers. In: Brammer AJ, Taylor E, eds. Vibration effects of thiso hand and arm in industry. New York: John Wiley, 1982:157-65

5 Gemne G, Pyykkö I, Taylor W, Pelmear PL. The Stockholm workshop scale for the classification of cold-induced Raynaud phenomenon in the hand-arm vibration syndrome (revision of the Taylor-Pelmear scale). Scand J Work Environ Health 1987;13:275-8.

6 Brammer AJ, Taylor W, Lundborg G. Sensorineural stages of the hand-arm vibration syndrome. Scand $J$ Work Environ Heal 1987;13:279-83.

7 Gemne G, Ekenvall L, Hansson J-E, Lidström I-M. Skadlig inverkan av hand-armvibrationer. En försäkringsmedicins bedömningsmodell, Arbete och Hälsa 1986;2:13-5

8 Fruhstorfer H, Lindblom U, Schmidt WG. Method for qure titative estimation of thermal thresholds in patients. $J$ Nemro Neurosurg Psychiatry 1976;39:1071-5.

9 Goldberg JM, Lindblom U. Standardised method of determiñn vibratory perception thresholds for diagnosis and screening i⿱⺈ neurological investigation. J Neurol Neurosurg Psychiatn 1979;42:793-803.

10 Ludin H-P. Electromyography in practive. Stuttgart-New Yor Georg Thieme Verlag, 1980.

11 Ekenvall L, Nilsson BY, Gustavsson P. Temperature and vibras tion thresholds in vibration syndrome. $\mathrm{Br} J$ Ind $\mathrm{Meg}$ 1986;43:825-9.

12 Pyykkö I, Korhonen O, Färkkilä M, Starck J, Aatola S, Jäntti V Vibration syndrome among Finnish forest workers, a follow-u from 1972 to 1983. Scand J Work Environ Health 1986;12. 307-12.

13 Bjerker N, Kylin B, Lidström I-M. Changes in the vibrator sensation threshold after exposure to powerful vibration. Worfo and Environmental Health 1970;7:3-7.

14 Taylor W, Pelmear PL, eds. Vibration white finger in industry. London: Academic Press, 1975:xxi. 